\title{
El Perú y el futuro de la Alianza del Pacífico
}

\author{
MBA Augusto A. MONJARAZ PACHECO
}

\section{RESUMEN}

Recientemente el Perú ha recibido dos noticias de gran importancia, la primera es la incorporación de la Bolsa de Valores de México al MILA (Mercados Integrados Latinoamericanos) al que pertenecen ya las Bolsa de Valores de Santiago, Lima y la de Caracas y la segunda de la publicación internacional especializada en turismo MASTER CARD 2014 GLOBAL DESTINATION CITIES INDEX que, en su cuarta edición, ubica a Lima entre las 20 ciudades receptoras de turismo más importantes del mundo.

La incorporación de la Bolsa de Valores de México al MILA, el pasado 18 de agosto, abre grandes posibilidades para el flujo de capitales a nuestro país provenientes de México y de Estados Unidos, a través de este último. El mercado de México es casi del mismo tamaño que todo el MILA agregado y tener acceso a un mercado que crece al doble propone enormes posibilidades para incrementar el ritmo de nuestro crecimiento en los próximos años.

Por otra parte las publicación de las TOP 20 Ciudades Destinos del Mundo, en la que Lima aparece por primera vez, con 5,1 millones de visitantes, muy cerca de Tokio y por encima de importantes ciudades latinoamericanas como Rio de Janeiro, Sao Paulo o Buenos Aires, significa un tácito reconocimiento internacional a la dinámica presencia de nuestro país en el mundo globalizado del siglo XXI. 
$\mathrm{Y}$ es que noticias como la señaladas no resultan casuales ni son opiniones exageradas si se considera el contexto en que nuestro país participa activamente en un significativo número de eventos internacionales que cada vez más lo involucran en las corrientes globalizadoras de crecimiento y desarrollo.

Estas opiniones ven a Lima convirtiéndose de manera silenciosa en el

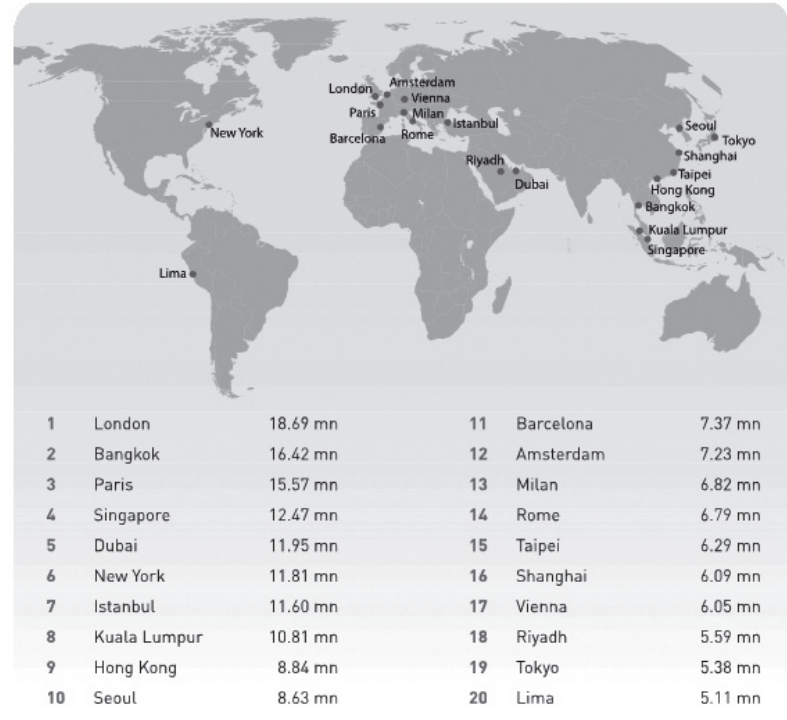

HUB comercial de la región, tanto por la activa participación del Perú en importantes bloques comerciales regionales, como la Comunidad Andina CAN y especialmente en la Alianza del Pacífico AP o comunidades globales como el Acuerdo de Asociación Transpacífico TPP, además de su actuación en APEC y los numerosos tratados comerciales, especialmente con Estados Unidos, la Unión Europea y las economías más grandes y dinámicas de Asia.

En la Comunidad Andina CAN, con una población de 101,0 millones de habitantes, integrada además por Bolivia, Colombia y Ecuador, nuestro país realiza negocios por más de U\$ 6,327 millones, de los cuales US\$2,361 son exportaciones con alto valor agregado. Las exportaciones intracomunitarias alcanzaron el año 2013 a US\$ 10,349 millones, de los cuales el 75\% o sea más de US\$ 7,000 millones son productos manufacturados.

Mayor importancia adquiere la corriente turística de estos países, que el 2013 fue superior a los 500,000 visitantes, de los cuales aproximadamente el $12 \%$ son personas de negocios.

De estas relaciones son destacables el flujo de visitantes y la calidad de las exportaciones, con mayor valor agregado que las que realizamos a terceros países. Sin embargo, debido a las políticas proteccionistas de Ecuador y Bolivia, se están registrando algunas restricciones al inter-

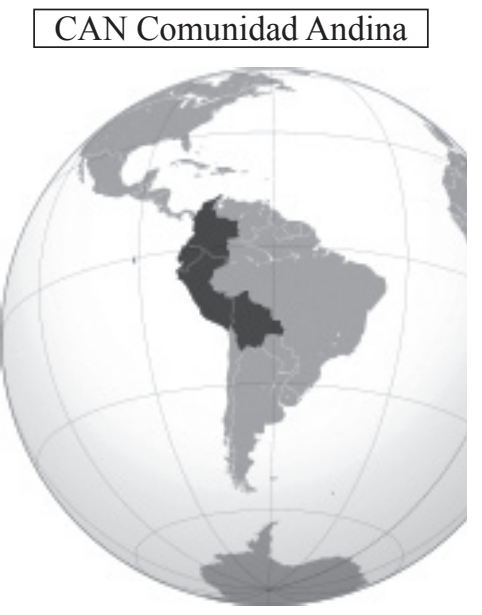


cambio que hacen dudar sobre la conveniencia de seguir perteneciendo a este bloque, aunque su clase empresarial mira a Perú no solo como mercado sino también como destino de sus inversiones y por supuesto, de sus viajes de recreo.

La Alianza del Pacífico AP, congrega a las economías de más rápido crecimiento en América Latina: Perú, Chile, Colombia, México y Costa Rica, juntas forman un PBI de 2,2 billones de dólares y un mercado conjunto de 214.1 millones de personas, más que la nación más grande de la región. Su contribución al PBI de América latina es de 36\%, representan el 55\% del comercio y recibe más del $45 \%$ de los flujos netos de inversión directa extranjera de América Latina, lo que significó durante el año 2103 un ingreso de US\$ 85,488 millones. Cuadro $\mathrm{N}^{\circ} 1$.

Genera una corriente turística hacia el Perú superior al millón de viajeros por año. Este dinámico bloque comercial ha demostrado altos indicadores de desempeño y estabilidad económica y en conjunto, representa la $8^{\text {a }}$ economía y la $7^{\mathrm{a}}$ potencia exportadora a nivel mundial.

La Alianza del Pacífico ha alcanzado un sostenido desarrollo, que le permite hoy en día ser uno de los bloques más sólidos de la región y una de las economías con mejor perspectiva a futuro. Este año, los países que integran el espacio regional (Chile, Colombia, Perú, México y Costa Rica) superaron por primera vez a los del Mercosur (Argentina, Brasil, Paraguay, Uruguay y Venezuela) en términos de recepción de inversión extranjera directa.

El crecimiento económico en Latinoamérica esta signado por la disparidad en el crecimiento de sus miembros, pues se estima que su crecimiento será de $2.5 \%$ en 2014 y $2.6 \%$ en 2015 , sin embargo esta expansión irá a dos ritmos. En opinión del BBVA "La Alianza del Pacífico crecerá a un ritmo que duplicará el de los países del Mercosur, la primera tendrá un incremento hasta de $3.8 \%$ en 2014 y $3.7 \%$ en 2015 y por su parte el segundo solo avanzara $1.5 \%$ este año y $1.8 \%$, el próximo".

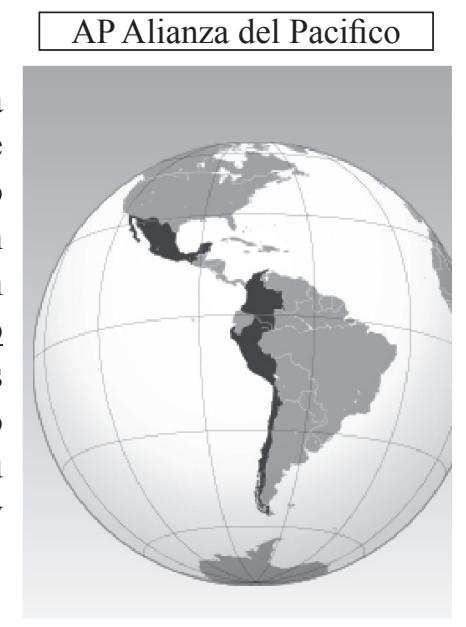




\section{Cuadro $N^{\circ} 1$}

\begin{tabular}{|c|c|c|c|c|c|c|c|c|c|c|}
\hline País & $\begin{array}{c}\text { Superficie } \\
\left(\mathrm{km}^{2}\right)\end{array}$ & $\begin{array}{c}\text { Población } \\
2013\end{array}$ & $\mid \begin{array}{c}\text { PIB (PPA) } \\
2013 \\
\text { (dólar } \\
\text { Intl.) } \\
\text { (millardos) }\end{array}$ & \begin{tabular}{|c|} 
PIB (PPA) \\
2013 \\
per cápita \\
(dólar \\
Intl.)
\end{tabular} & \begin{tabular}{|c} 
PIB \\
(Nominal) \\
2013 \\
(USD) \\
(millardos)
\end{tabular} & $\begin{array}{c}\text { PIB } \\
\text { (Nominal) } \\
\text { per cápita } \\
2013 \text { (USD) }\end{array}$ & $\begin{array}{c}\text { IDH } \\
2013\end{array}$ & $\begin{array}{c}\text { Exporta } \\
\text { ciones } \\
2012 \\
\text { (USD) } \\
\text { (millones) }\end{array}$ & \begin{tabular}{|c} 
Importa- \\
ciones \\
2012 (USD) \\
(millones)
\end{tabular} & $\begin{array}{c}\text { IED } \\
2012 \text { (USD) } \\
\text { (millones) }\end{array}$ \\
\hline Chile & 756,102 & $16,823,000$ & 340.093 & 19.475 & 291.115 & $16,273.038$ & 0.819 & 83,660 & 70,200 & 20,400 \\
\hline Colombia & $1,138,910$ & $47,151,000$ & 532.653 & 11.284 & 394.134 & $8,237.727$ & 0.719 & 59,960 & 55,490 & 16,833 \\
\hline $\begin{array}{l}\text { Rica } \\
\end{array}$ & 51,100 & $4,718,000$ & 62.300 & 13.205 & 48.886 & $10,362.61$ & $\mid 0.773$ & 11,470 & 16,790 & 2,265 \\
\hline \begin{tabular}{|l|l|l|}
1 & México \\
\end{tabular} & $1,964,375$ & $\mid 116,021,000$ & $1,834.438$ & 15.932 & $1,277.369$ & $10,989.103$ & 0.775 & 370,900 & 379,400 & 35,100 \\
\hline \begin{tabular}{|l|l|} 
Perú \\
\end{tabular} & $1,285,216$ & $30,946,000$ & 347.293 & 11.403 & 215.222 & $7,135.888$ & 0.741 & 47,380 & 41,150 & 12,240 \\
\hline Total & $5,195,703$ & $216,659,000$ & $3,110.538$ & $14,356.84$ & $2,212.650$ & $10,212.59$ & 0.767 & 573,870 & 563,030 & 86,565 \\
\hline
\end{tabular}

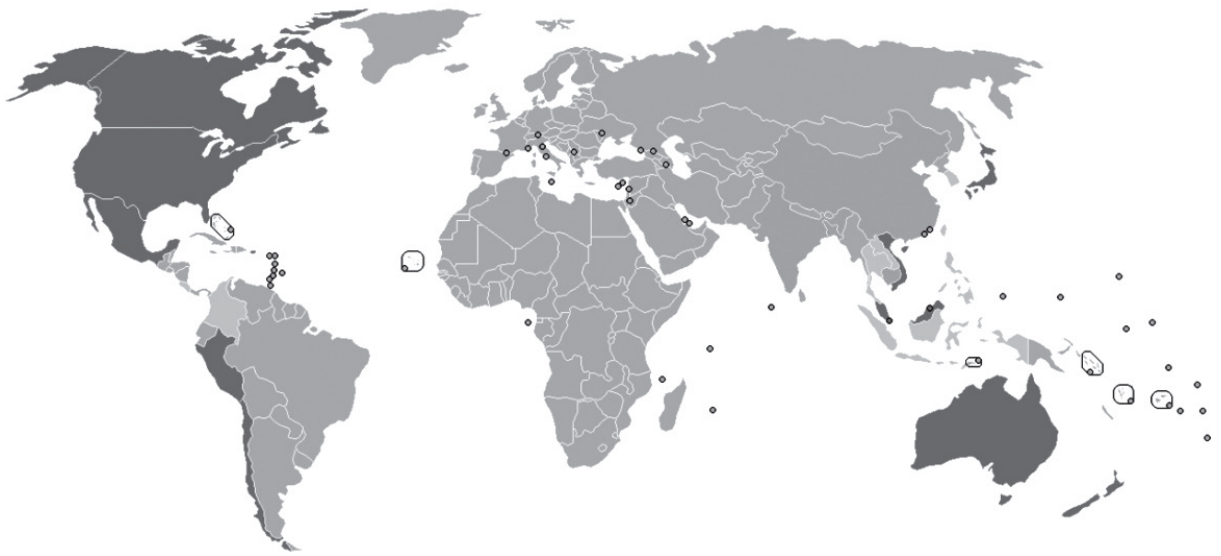

TPP Acuerdo de Asociación Trans Pacífico

Al seno de APEC y para reafirmar el sentido práctico de sus accionar se está consolidando un nuevo bloque comercial con la activa participación del Perú y que le ofrece las mejores perspectivas para su crecimiento: el Acuerdo de Asociación Transpacífico TPP, integrado Australia, Brunei, Canadá, Chile, Estados Unidos, Malasia, México Nueva Zelandia, Singapur y Viet Nam e Indonesia y Japón como observadores, con una población que supera los 800 millones de habitantes.

En este gigantesco bloque comercial tanto el Peru como la Alianza del Pacífico hacen grandes esfuerzos por estrechar lazos comerciales, financieros y tecnológicos con el firme propósito de acelarar el camino hacia el desarrollo. El Acuerdo de Asociación Trans Pacífico TPP es una oportunidad mayúscula para consolidar la presencia del Perú y del bloque de Alianza del Pacífico en la región Asia-Pacífico, que ofrece un mercado diversificado para el desarrollo de nuevos productos de exportación, el comercio de servicios, la atracción de inversiones, la movilidad de personas de negocios, entre otros. 
En el 2012 el intercambio comercial del Perú con los 11 países involucrados en la negociación representó el $32.3 \%$ del total, equivalente a 28.5 mil millones de dólares. Los principales sectores exportadores fueron minería, agricultura y textil-confecciones.

Si fuese posible sobreponer estos gráficos uno sobre el otro resultaría Lima siendo el epicentro de su actividad y explicaría mejor el por qué desde fuera nos ven con más optimismo a los peruanos que nosotros mismos y porque el Perú y Lima, en particular, adquieren un atractivo creciente para el mundo.

En este análisis, de las relaciones comerciales de Perú con el exterior, no solo se consideran las cifras absolutas del comercio de bienes sino también la calidad de estos, el comercio de servicios y el flujo de capitales.

Así, mientras el comercio de bienes con sus socios de la Comunidad Andina CAN viene registrando serios y continuos reveces, sobre todo con Ecuador, lo que ha despertado dudas sobre la conveniencia de continuar en este bloque, el movimiento de personas viene incrementándose en proporciones que superan el $11 \%$, así como un creciente flujo de empresarios y capitales provenientes de los tres países miembros. En consecuencia, más allá de las opiniones adversas, el Perú está obligado redoblar sus esfuerzos para convocar a sus socios de la CAN y dinamizar sus relaciones en busca de sus objetivos de mediano y largo alcance relacionados con;

- Promoción y desarrollo de la pymes.

- Exportación de bienes con mayor valor agregado.

- Exportación de servicios, especialmente turísticos.

- Movimiento positivo de capitales.

Al interior de la Alianza del Pacífico nuestro país persigue los mismos objetivos que en la CAN y además, en esfuerzo conjunto con sus socios, busca "Construir, de manera participativa y consensuada, un área de integración profunda para avanzar progresivamente hacia la libre circulación de bienes, servicios, capitales y personas". Y como bloque la Alianza del Pacífico busca concretar sus propósitos de integración al mercado global y dirige sus esfuerzos a: "Impulsar un mayor crecimiento, desarrollo y competitividad de las economías de las Partes, con miras a lograr mayor bienestar, superar la desigualdad socioeconómica e impulsar la inclusión social de sus habitantes" (AP)

Pero es, en sus relaciones con los países miembros de la TPP, que la Alianza del Pacífico como bloque y cada uno de sus miembros individualmente, se proponen logros más ambiciosos y de mayor alcance: "Convertirse en una plataforma de articulación política, integración económica y comercial, y proyección al 
mundo, con énfasis en la región Asia-Pacífico" (AP). La participación en este bloque deberá centrarse esencialmente en los siguientes objetivos:

- La intensificación de las exportaciones tradicionales: "commodities".

- La diversificación de sus mercados para el desarrollo de nuevos productos.

- El comercio de servicios, en especial la movilidad de personas.

- La atracción de inversiones y la transferencia de tecnología.

En medio de este panorama, la Alianza del Pacífico juega un rol de bisagra entre estos bloques, asegurando para sus asociados sus propios objetivos y los señalados para la TPP. Se trata entonces de afinar sus habilidades negociadoras en los campos comercial y diplomático para alcanzar los logros que busca en lo político y económico, en el que cada uno de estos bloques y los tratados comerciales, suscritos por sus miembros con las principales economías del mundo, desempeñan roles diferentes pero congruentes con sus objetivos institucionales:

Según las proyecciones del FMI, el PBI de la Alianza del Pacífico tendrá un avance de 34.6\% en los próximos 5 años. "En el 2018 se constituirá en el tercer bloque económico del planeta, solo superado por los países que integran el acuerdo Asia- Pacífico (Asean) y los llamados Brics (Brasil, Rusia, India, China y Sudáfrica). Hoy la AP representa la sexta economía del mundo por encima de Rusia y Brasil y para el 2018 será la quinta por encima de la propia Alemania" y el Perú está en medio. 